\title{
V3. VIGILÂNCIA DAS COBERTURAS VACINAIS UTILIZANDO INDICADORES ACTUADOS NO SISTEMA ÚNICO DE SAÚDE BRASILEIRO.
}

Rui Moreira Braz ${ }^{1}$; Carla Magda Allan S. Domingues ${ }^{1}$; Antônia Maria da Silva Teixeira ${ }^{1}$; Expedito José de Albuquerque Luna² ${ }^{2}$.

${ }^{1}$ Coordenação Geral do PNI/DEVIT/SVS/MS;

2 Instituto de Medicina Tropical de São Paulo, Universidade de São Paulo.

INTRODUÇÃO Apesar das coberturas vacinais adequadas serem observadas nos âmbitos nacional e estadual, o mesmo não ocorre nos municípios onde as coberturas são heterogêneas.

OBJETIVO Apresentar classificação de risco de transmissão de doenças imunopreveniveis nos municípios utilizando indicadores pactuados no sistema único de saúde para vigilância das coberturas vacinais

METODOLOGIA Foram avaliados cinco indicadores para vigilância das coberturas de dez vacinas do calendário da criança menor de dois anos: cobertura vacinal e homogeneidade de coberturas, ambos pactuados pelos gestores do sistema único de saúde, taxa de abandono, proporção de crianças menores de dois anos vivendo em municípios com cobertura vacinal adequada e risco de transmissão de doenças imunopreveníveis no município. $\mathrm{O}$ indicador de risco foi classificado em muito baixo, baixo, médio, alto e muito alto.

RESULTADOS No ano de 2014, dos 5.570 municípios brasileiros, 11,97\% alcançaram coberturas adequadas para as dez vacinas e $31,87 \%$ para oito ou nove vacinas, totalizando $43,84 \%$ os que atingiram as metas de cobertura e homogeneidade pactuadas. Em 667 (12,0\%) dos municípios a homogeneidade foi adequada para o Programa de Qualificação das Ações de Vigilância em Saúde (PQAVS). Em outros 1.775 (31,9\%) municípios a homogeneidade atendeu aos requisitos previstos no Contrato Organizativo de Ação Publica da Saúde (COAP), em 2.801 (50,3\%) a homogeneidade foi baixa ou muito baixa e em 327 (5,9\%) foi zero. No grupo de risco muito baixo para transmissão de doenças imunopreveníveis foram observados $11,97 \%$ dos municípios, no de risco baixo, 29,62\%, no de risco médio, 2,24\%, no de risco alto, $54,34 \%$ e no grupo de risco muito alto, $1,85 \%$. 
CONCLUSÃO A vigilância da situação vacinal nos municípios permitiu identificar: maioria dos municípios em situação de alto risco; inexistência de informação da situação vacinal em alguns municípios; coberturas vacinais com valores altos e atípicos; variação nas taxas de abandono desde valores negativos até abandono completo de algumas vacinas; quantidade significativa de municípios com homogeneidade igual a zero; minoria das crianças vivendo em municípios com cobertura adequada. A vigilância de risco das coberturas utilizando indicadores pactuados no sistema único de saúde oferece nova ferramenta para identificação de áreas prioritárias onde as ações de controle poderão ser realizadas com maiores chances de acerto pelos gestores para melhorar a qualidade e o sucesso do programa de imunizações.

PALAVRAS-CHAVE coberturas vacinais, vigilância, monitoramento, risco. 